Educación Física y Ciencia, vol. 21, n4, e103, octubre-diciembre 2019. ISSN 2314-2561

Universidad Nacional de La Plata.

Facultad de Humanidades y Ciencias de la Educación.

Departamento de Educación Física

\title{
Formação Superior em Educação Física no Brasil: um estudo de caso
}

Higher Formation in Physical Education in Brazil: a case study

\section{Leon Ramyssés Vieira Dias}

Grupo de Estudos e Pesquisas Vitor Marinho (GEPVM -UFRJ), Brasil

leon_mv1@hotmail.com

André Malina

Universidade Federal do Rio de Janeiro (PPGTDS/EEFD, Brasil

andremalina@yahoo.com.br

Sílvio de Cássio Costa Telles

Universidade Estadual do Rio de Janeiro (PPGCEE), Brasil

silviotelles@terra.com.br

Antônio Cláudio Gomez de Sousa

Universidade Federal do Rio de Janeiro, Brasil

ac@poli.urj.br

Angela Celeste Barreto de Azevedo

Universidade Federal do Rio de Janeiro, Brasil

angelaestagio@yahoo.com.br

\section{ReSUMO:}

A formação superior em Educação Física vem sendo cada vez mais discutida por pesquisadores da área. Hoje, o curso é dividido em licenciatura e bacharelado, regulamentados pelas Resoluções CNE/CP 01/02 e CNE/CES 07/04, respectivamente. Com a nova Resolução (CNE/CES, 584/2018) que aguarda homologação, no entanto, dentre outras modificações, será possível que as Instituições de Ensino Superior ofereçam as duas formações em um único currículo. Em posse de tal debate, o presente artigo tem como objetivo geral comparar e analisar os Projetos-Político-Pedagógicos de uma Universidade Federal que oferece, em currículos distintos, os cursos de licenciatura e bacharelado. A partir de uma ampla coleta de dados, utilizou-se uma metodologia de estudo de caso para retratar as possíveis aproximações e os possíveis distanciamentos entre os cursos de licenciatura e bacharelado nas Universidades Federais. Além disso, os dados foram também tratados qualitativamente inspirados no princípio educativo de Antonio Gramsci. Como resultado, pôde-se observar que há uma ampla gama de disciplinas comuns aos dois cursos, bem como uma proposta de formação aproximada, apesar de serem oferecidos separadamente. Desse modo, concluiu-se que a oferta do curso de Educação Física separadamente pode ser reconceptualizada e repensada a partir das novas Diretrizes Curriculares.

Palavras-chave: Universidades, Formação Profissional, Diretrizes Curriculares, Projeto Político, Pedagógico.

\section{ABstract:}

The Higher Formation in Physical Education has been increasingly discussed by researchers in the field. Currently, the course is divided into undergraduate and baccalaureate degrees, regulated by Regulations CNE / CP 01/02 and CNE / CES 07/04, respectively. A new regulation (CNE / CES, 06/2018), criticized by Physical Education researchers, among other modifications, 
makes it possible for Higher Education Institutions to offer two formations in a single curriculum. From this situation, this article aims to compare and analyze the Projects-Political-Pedagogical of a Federal University that offers, in different curricula, undergraduate and baccalaureate. From a broad data collection, a case study methodology was used to portray the possible approximations and the possible distancing between undergraduate and baccalaureate at Federal Universities. In addition, the data were also treated qualitatively inspired by the educational principle of Antonio Gramsci. As a result, it may be noted that there is a wide range of disciplines common to both courses, as well as a formation proposal, but they are offered separately. Thus, we concluded that the offer of the Physical Education course can be reconceptualized and rethought from the new Curricular Guidelines.

KEYWORDs: Universities, Professional Formation, Curricular Guidelines, Project, Political, Pedagogical.

\section{1) INTRODUÇAO}

Uma das questões debatidas no ambiente acadêmico trata da formação profissional em Educação Física. Diante dessa questão, emergem outras com significância, como é o caso do currículo e dos Projetos Políticos Pedagógicos (PPPs) subjacentes à formação profissional em Educação Física, diante da legislação que determina, em parte, como deverá ser a formação (Azevedo, 2016; 2013)

Neira (2017), no entanto, sugere que ainda não está repercutida na forma de pesquisa a questão do currículo da formação de professores de Educação Física. Já Antunes (2007), em perspectiva diversa, defende a necessidade de uma correlação direta entre formação profissional e atendimento às demandas do mercado. Esta visão de Antunes (2007) é criticada por autores que tratam, por exemplo, da questão do currículo escolar em uma perspectiva crítica e emancipatória (Betti, Knijnik, Venâncio, Sanches Neto y Daólio, 2014); ou dos currículos da formação em Educação Física em termos internacionais (Lupton, 2003).

Já a atuação de professores em currículos não tradicionais (integrados ou transdisciplinares, por exemplo) parece apresentar dificuldades (Rivilla, Garrido e Gonçalves, 2011) justificadas pelo processo de escolarização, visto que têm sido impulsionadas pesquisas que identifiquem e respondam, sobre a formação de professores, se há uma construção de algum "modelo valioso y representativo que facilite la formación integral del profesorado universitario y lesitúe como el experto en el saber académico, lãs prácticas docentes y el creador de una línea de investigación e innovación de la docência universitaria?” (p. 123).

Também a atuação dos professores de Educação Física na formação superior não reflete, necessariamente, uma compreensão conceitual acerca da Educação Física, o que Vieira e Neira (2016) chamam de ecletismo conceitual e, os mesmos autores, definem como característica de um hibridismo curricular.

Nesse contexto, sobre o debate se a Educação Física no Brasil deve ter uma formação única ou ampliada ou uma formação distinta com dois cursos e projetos não alcançam consenso. No entorno do debate, emerge a questão do currículo e da formação profissional que é tratada tradicionalmente no ambiente acadêmico em Educação (Goodson, 2008; Silva 2002). Sem ignorar os fundamentos trazidos por essa área, cabe expor que existem especificidades da Educação Física, tratadas na Resolução CNE/CP 01/02 (Brasil, 2002) das Diretrizes Curriculares Nacionais que definem os termos para reformulação e elaboração do projeto pedagógico dos cursos de licenciatura em Educação Física, enquanto a formação do bacharel em Educação Física é regida pela Resolução CNE/CES 07/04 (Brasil, 2004). As Instituições de Ensino Superior devem seguir a legislação vigente, mas tem autonomia na construção dos próprios projetos pedagógicos de curso, mas são obrigadas a oferecê-los com projetos pedagógicos e uma matriz curricular distinta.

Faz-se relevante, no entanto, realçar o momento atual de aguardo da homologação da Resolução que institui as novas Diretrizes Curriculares dos cursos de Graduação em Educação Física, conforme Parecer aprovado de três de outubro de 2018 do Conselho Nacional de Educação (Brasil/CNE/CES, 584/2018). Mais ainda, saliente-se que tal Parecer traz, no Projeto de Resolução, dentre outras modificações, no Art. 80, que: 
As Instituições de Educação Superior poderão, a critério da Organização do Projeto Pedagógico Curricular do Curso de Educação Física, admitir, em observância do disposto nesta Resolução, a dupla formação dos matriculados em bacharelado e licenciatura (p. 14).

O suposto contido no enunciado permite, na forma descrita, que haja a formação unificada no Brasil, alterando a atual legislação e dando novas possibilidades às Instituições de Ensino Superior. Dado que o período de transição e adaptação das instituições às novas Diretrizes Curriculares de Educação Física está previsto para até dois anos após a publicação da Resolução, cabe, aqui, contribuir academicamente com o processo de reformulação curricular porvir.

Nesse sentido, o presente artigo está estruturado como um estudo de caso a partir de uma pesquisa teóricoempírica e tem como objetivo geral comparar e analisar os PPPs ${ }^{1}$ de uma importante Universidade Federal que oferece os cursos de licenciatura e bacharelado (ainda nos moldes da Resolução CNE/CP 01/02 e da Resolução CNE/CES 07/04, respectivamente) em Educação Física, buscando evidenciar as semelhanças, as diferenças e as particularidades de cada PPP. Tem-se, ainda, como objetivo específico, verificar e compreender a proposta de formação trazida pelo curso de Educação Física nessa universidade.

O presente artigo de pesquisa visa retratar aspectos dos currículos de cursos de EF no Brasil, a partir das resoluções vigentes, em licenciatura e bacharelado (Brasil 2002; 2004) para pensar currículos que serão construídos após a homologação da Resolução 584/2018.

Como suporte teórico da investigação de pesquisa, no item 6 da análise geral, utilizou-se o princípio educativo de Gramsci (2001) embasado nas relações sociais e técnicas pelas quais o homem produz sua existência. Esse autor encontra na escola humanista, de cultura geral, as condições objetivas para cada indivíduo desenvolver a capacidade de pensar e dirigir-se na vida. Esse princípio educativo é uma referência gramsciana para o desenvolvimento da articulação com uma escola unitária.

\section{2) Aspectos Metodológicos}

$\mathrm{O}$ artigo caracteriza-se como um estudo de caso procurando, no aspecto descritivo, evidenciar o máximo de informações possíveis sobre o que se deseja pesquisar. Além disso, o estudo de caso permite fornecer o conhecimento aprofundado de uma realidade delimitada cujos resultados atingidos podem permitir e formular o encaminhamento de outras pesquisas ou para outros casos semelhantes. Na visão de Triviños (1987) "estes estudos têm por objetivo aprofundarem a descrição de uma determinada realidade" (p.110).

Desse modo, para delinear o objeto de pesquisa na forma de estudo de caso, foram pautados passos e procedimentos de pesquisa sob o formato dedutivo, recorrendo-se a uma coleta de dados inicial de âmbito nacional, com uma consideração preliminar que permitisse chegar à análise pretendida.

Por outro lado, por necessidades intrínsecas ao tipo de investigação, e a partir dos dados levantados inicialmente, a metodologia de estudo de caso foi utilizada para juntar-se ao método de pesquisa teóricoempírica, complementando e ampliando informações. O método de pesquisa teórico-empírica foi escolhido por permitir, de forma mais clara, reconstruir teorias, conceitos, ideologias, ideias, analisar as condições explicativas da realidade e traçar discussões pertinentes a partir da construção teórica. Além disso, pode oferecer maior concretude às argumentações, pois dependerá do referencial teórico, agregando impacto pertinente ao aproximar-se da prática (Baffi, 2002).

Nesse sentido, a pesquisa foi realizada com base metodológica mista (ou multirreferenciada), aliando a pesquisa teórico-empírica ao estudo de caso com uma análise documental, retratando, especificamente, uma instituição. Nesse sentido, este estudo de caso tem foco em uma unidade e tem característica intrínseca, pois, para Ventura (2007) “examina um caso para se compreender melhor outra questão, algo mais amplo, orientar estudos ou ser instrumento para pesquisas posteriores” (p. 384). Em que pese os cuidados a serem tomados, como descrito por Ventura (2007), para Meirinhos e Osório (2010), o estudo de caso deve possuir 
[...] um conjunto de características que ajudam a dar forma à metodologia dos estudos de caso, como a natureza da investigação [...], o seu carácter holístico, o contexto e sua relação com o estudo, a possibilidade de poder fazer generalizações, a importância de uma teoria prévia e o seu carácter interpretativo constante (p. 52).

Sob o aspecto da análise documental, cabe ressaltar que, conforme afirma Gil (2008) "a pesquisa documental vale-se de materiais que não recebem ainda um tratamento analítico, ou que ainda podem ser reelaborados de acordo com o objetivo da pesquisa" (p.45).

\subsection{Passos e Procedimentos Metodológicos}

Com o objetivo de escolher as Instituições de Ensino Superior participantes do estudo, a coleta dos dados ocorreu em três momentos. No primeiro momento, foi realizada uma pesquisa no sítio eletrônico do Ministério da Educação ${ }^{2}$ encontrando um número total de sessenta e três (63) Universidades Federais. Dessas sessenta e três (63) instituições, foram separadas cinqüenta e seis (56) Universidades Federais, que possuíam página na internet disponível para acesso. Das cinqüenta e seis (56) universidades federais pesquisadas, foram separadas apenas aquelas que ofereciam as duas formações (licenciatura e bacharelado), quantificando um total de vinte e duas (22) instituições pertencentes às diferentes regiões do país.

No segundo momento foram analisados os PPPs das instituições com cursos de licenciatura e bacharelado para verificar o percentual de disciplinas iguais ou equivalentes ${ }^{3}$. A relação de igualdade ou equivalência entre esses cursos foi feita comparando as disciplinas do curso de bacharelado com o curso de licenciatura ${ }^{4}$. Foram encontradas dezenove (19) Universidades Federais ofertando ambos os cursos com graus de igualdade ou equivalência superior a cinquenta por cento ou mais ( $\geq 50 \%$ ), como mostra o Quadro 1.

QUADRO 1:

Universidades Federais por regiões e a relação de igualdade

ou equivalência das disciplinas do bacharelado na licenciatura

\begin{tabular}{|l|l|l|}
\hline Disciplinas iguais ou equivalentes & Universidades Federais por Regiões & Total \\
\hline do bacharelado na licenciatura (\%) & & \\
$\geq 50 \%$ & Sorte -1 & \\
& Sudeste -6 & 19 \\
& Nordeste -7 & \\
\hline
\end{tabular}

Fonte: Os autores (2018)

Da coleta de dados, optou-se por analisar a Universidade Federal pesquisada - aqui chamada de Universidade 1 - porque retrata a média de equivalência próxima de 50\% entre as disciplinas do curso de bacharelado em relação ao curso de licenciatura. Dessa forma, a proximidade percentual de igualdade entre os cursos garante a possibilidade de evidenciar tanto aproximações quanto distanciamentos dos currículos, evitando que as análises e conclusóes por inferência possam ser mais tendenciosas ou equivocadas.

Visando observar a proposta de formação e o grau de equivalência entre os cursos da Universidade 1, foram selecionados e coletados os seguintes documentos: o Projeto Político-Pedagógico (PPP) ${ }^{5}$ e os Planos 
de Curso das disciplinas em Educação Física ofertados nos dois cursos com acesso direto às fontes originais, contribuindo para manter a fidedignidade da pesquisa.

Os documentos foram analisados de forma cruzada, visto que o PPP não traz informações relevantes que estão contidas apenas no Plano de Curso das disciplinas. Foram feitos cruzamentos entre: a) entre os próprios PPPs da licenciatura e do bacharelado; b) o PPP da licenciatura e o Plano de Cursos das disciplinas da licenciatura; c) o PPP do bacharelado e o Plano de Cursos das disciplinas do bacharelado, e; d) o Plano de Curso das disciplinas da licenciatura com o Plano de Curso do bacharelado.

Dessa maneira, foram analisados os conteúdos pertinentes ao PPPs da licenciatura e do bacharelado, tanto comum aos dois cursos quanto diferentes. Logo, foram descritos quatro tópicos:

1. A concepção de currículo (item 3.1/comum aos cursos);

2. Os objetivos (item 3.2/comum aos cursos);

3. O perfil do egresso (item 3.3/comum aos cursos);

4. As disciplinas, Carga Horária e Ementas (item 3.4 licenciatura; item 3.5 bacharelado).

Posteriormente, após a descrição e o cruzamento dos dados levantados, foi feita uma análise do material empírico, dialogando semelhanças e diferenças entre os currículos. $\mathrm{Na}$ análise dos dados (item 4) foram comparadas e analisadas: as disciplinas, as cargas horárias e as ementas dos cursos (item 4.1); as disciplinas comuns aos cursos (item 4.2); o Plano de Curso das disciplinas que são comuns aos cursos e que estavam disponíveis no sítio eletrônico da Universidade 1 (item 4.3), a fim de encontrar em quais desses tópicos os planos de curso convergem ou divergem do PPP. Desse modo, analisamos 16 disciplinas em que seus Planos de Curso estavam disponíveis para o acesso, tanto na modalidade de licenciatura quanto na modalidade de bacharelado.

Com o processo de descrição, comparação e análise dos dados levantados foi possível desenvolver algumas considerações (item 5) para, em seguida, unindo teoria e empiria, será realizada uma análise geral (item 6) utilizando-se como referencial o conceito de princípio educativo proposto por Gramsci ${ }^{1} 4$.

\section{3) DESCRiÇAo E APRESENTAÇAO dos DADOS EMPÍRICOS}

O PPP da licenciatura e bacharelado em Educação Física da Universidade 1 têm suas versões mais recentes redigidas no ano de 2006. Neles encontram-se diversas informações para compreender: 1- O contexto histórico em que o local dos cursos de educação física da Universidade 1 foi criado; 2- A concepção de currículo adotada pela escola; 3- O currículo com as disciplinas que formam a matriz curricular; 4- As ementas; 5- Demais informações miscelâneas que podem ser relevantes para entender a proposta de formação prescrita.

Vale destacar que apesar da divisão do currículo em dois cursos distintos existem muitos objetivos em comum entre a licenciatura e o bacharelado, explicitados ao se encontrar diversos tópicos nos PPPs que possuem a mesma redação. Desse modo, apesar das formaçóes terem atuações profissionais em campos distintos, a proposta de formação da instituição pode atender a princípios básicos comuns nos dois cursos.

\subsection{A Concepção de Currículo da Universidade 1}

A Concepção de Currículo apresentada pela Universidade 1 é a mesma para os cursos de licenciatura e bacharelado em Educação Física. Desse modo, os PPPs (2006a; 2006b) trazem a seguinte concepção de currículo prescrita:

A exemplo de outras áreas profissionais, também na Educação Física surgiram inúmeras mudanças. É preciso criar nos novos profissionais a consciência e a motivação para a sua formação contínua, acompanhando as evoluções do seu tempo. Hoje, não 
há mais espaço no mercado de trabalho para profissionais que concluam seus cursos de graduação e cessem a sua formação. É necessária uma busca permanente pelo aprimoramento e pelos estudos mais avançados no seu campo de atuação. (p.8).

Nota-se que o documento prescrito atribui importância a uma formação de profissionais interessados na formação contínua, para que possam atender às demandas do mundo do trabalho. Por outro lado, os currículos devem proporcionar aos professores uma formação que permita o desenvolvimento de um pensamento crítico, além de autonomia para buscar a sua própria formação contínua. Segundo os próprios PPPs (2006a; 2006b):

A formação do professor é hoje tema de debate de especialistas de diferentes países. Destacam-se as proposições de Gimeno Sacristán [...], Philippe Perrenoud e António Nóvoa, entre outros. Um dos pontos de convergência no pensamento desses autores é o entendimento de que a formação inicial do professor deve ser dirigida para que o profissional se torne reflexivo e crítico, com uma base sólida na graduação, mas também preparado para buscar a sua formação contínua e de modo autônomo (p.8).

Partindo do entendimento que é necessário formar professores críticos, reflexivos e autônomos, no entendimento da Universidade 1, o currículo deve contemplar a formação do aluno para que ele, na condição de professor, possua conhecimentos pertinentes de quatro fontes. Segundo os PPPs (2006a; 2006b) as fontes de conhecimento se referem a:

saberes da formação profissional (das ciências da educação e da ideologia pedagógica mobilizada em conformidade com essa atividade, transmitidos pelas instituições formadoras);

saberes das disciplinas (que correspondem aos saberes sociais sistematizados e tematizados na instituição universitária);

saberes curriculares (saberes sociais que a escola/ sociedade selecionou para serem transmitidos às futuras gerações);

$\mathrm{e}$

saberes da experiência (desenvolvidos pelo professor no exercício da profissão) (p.9).

Pela experiência e contato com os elementos supracitados, o profissional desenvolveria seu conhecimento para atuação docente. Os PPPs também defendem a importância da pesquisa para a formação do estudante, de forma a incentivá-lo em vários campos do conhecimento. Há uma preocupação na proposta curricular prescrita com a pesquisa e a extensão como formas de complementar a formação acadêmica.

Ainda no que se refere à formação dos professores, a Universidade 1 compreende que há dicotomia na relação teoria e prática, mas que esta pode minimizada oferecendo-se disciplinas que contemplem a fundamentação pedagógica concomitantemente com aquelas que objetivam conhecimentos teóricos e das ciências básicas. Além disso, a concepção de currículo considera a educação como prática social multidimensional sendo própria do trabalho docente, a capacidade de interpretar e problematizar, com autonomia, a realidade educacional em diferentes contextos políticos, sociais e econômicos. Ou seja, para Universidade 1 isso significa:

a) a articulação do ensino com a pesquisa/investigação;

b) a busca cotidiana e sistemática de compreensão da complexidade da prática pedagógica, nela incluídos os processos de ensino-aprendizagem e as questóes de currículo e ensino e os fatores políticos, econômicos, sociais e culturais que afetam a vida escolar;

c) a articulação dos conhecimentos anteriormente citados com aqueles que constituem os objetos de ensino dos futuros docentes (PPP,2006a 2006b p.10).

Assim, compreende-se que a Universidade 1 prioriza a construção de currículos para formar profissionais que entendam a realidade contemporânea da Educação Física, atendam necessidades pragmáticas do mundo do trabalho e formem profissionais críticos, capazes de compreender as questões da sociedade. 


\subsection{Os Objetivos do Curso}

A licenciatura e o bacharelado reiteram suas propostas de formação em seus objetivos gerais, que aparecem no PPP (2006a; 2006b) de forma comum aos dois cursos:

Preparar professores licenciados em Educação Física para uma atuação reflexiva, crítica, transformadora e democrática em função dos direitos, necessidades e interesses da maioria da população brasileira;

Estimular o processo de formação contínua dos futuros professores, através do interesse pela busca e produção de novos conhecimentos advindos de pesquisas científicas e práticas de extensão, visando seu aperfeiçoamento permanente. (p.19).

Destaca-se nos PPPs a relação entre a concepção de currículo e os objetivos gerais do curso, pois partem da premissa de formar profissionais críticos e atuantes na sociedade. Ainda, conforme a perspectiva da Universidade 1, espera-se que esses profissionais sejam capazes de defender os interesses da maioria da população e que continuem a estudar através da pesquisa e da formação continuada.

No entanto, os objetivos específicos dos cursos se diferenciam. A licenciatura (2006a) propõe:

[...] desenvolver as competências técnicas para o planejamento, execução e avaliação das atividades docentes na área de Educação Física, dirigidas à Educação Infantil, ao Ensino Fundamental e ao Ensino Médio (p.15).

Por outro lado, o bacharelado (2006b) tem por objetivo específico:

[...] desenvolver as competências técnicas para o planejamento, execução e avaliação das atividades docentes na área de educação física, dirigidas aos diversos segmentos da sociedade nos âmbitos: dos esportes e da cultura da atividade física; da saúde preventiva; da promoção da boa qualidade de vida; do atendimento às demandas provenientes do envelhecimento da população; do lazer; da pessoa portadora de necessidades especiais e das minorias sociais (p.15-16).

As competências atribuídas à licenciatura são de preparar o profissional para atuar em diferentes níveis da Educação Básica através do desenvolvimento de competências técnicas para planejar, executar e avaliar. Já o curso de bacharelado mostra maior preocupação com a atuação voltada para a área da saúde, mas com uma proposta parecida com a licenciatura, de profissional que saiba lidar com as diferentes situaçóes na vida profissional e seja motivado à formação continuada.

\subsection{Perfil do Egresso}

No tópico "Perfil do Egresso" também está exposta a proposta de profissional que se pretende formar. O curso de licenciatura e de bacharelado possuem pontos em comum (PPP, 2006a; 2006b), dentre os quais destaca-se os seguintes:

tenha consciência de seu papel como educador, sendo capaz de intervir pedagógica e profissionalmente junto às diferentes manifestações das culturas das atividades físicas e dos esportes, levando em consideração a diversidade do público alvo;

apresente uma clara visão pedagógica e científica, dominando instrumentos, métodos e técnicas de pesquisa que permitam intervenções em sua prática profissional;

demonstre atitude crítico-reflexiva perante a produção de conhecimento da área, visando obter subsídios para o aprimoramento constante de seu trabalho no âmbito da Educação Física;

demonstre compreender e dominar o processo de intervenção profissional nos campos de trabalho relacionados à tradição da área e nas suas relações com o contexto no qual estão inseridos;

demonstre saber como considerar criticamente as características, interesses e necessidades e as diversidades dos alunos das pessoas nos momentos de planejamento, aplicação e avaliação dos programas de intervenção profissional;

demonstre capacidade de argumentação de modo que saiba justificar e articular sua visão de mundo e sua prática profissional, bem como balizar sua intervenção profissional à luz das teorias produzidas a partir dos campos de conhecimento específicos e afins; 
possua uma ampla visão da realidade social, política, cultural e econômica do País, consciente das reais necessidades e possibilidades do cidadão (p.15-16).

\subsection{Disciplinas, Carga Horária e Ementas: Licenciatura}

Através das disciplinas, ementas e referências bibliográficas, torna-se possível observar se o objetivo geral do curso está em acordo com a formação que os discentes estão submetidos. O curso de licenciatura em Educação Física possui uma carga horária total de 2.970 horas, dividido em oito períodos. A carga horária total do curso divide-se em: 34 Disciplinas Obrigatórias, equivalentes a 1.890 horas; 360 horas de Disciplinas de Livre Escolha; 400 horas de Estágio Curricular Supervisionado de Ensino de Educação Física; 120 horas de monografia e; 200 de Atividades Complementares.

As 34 Disciplinas Obrigatórias do curso de licenciatura são divididas em Formação Ampliada e Formação Específica, e são subdivididas em:

1. Na formação Ampliada;

a) Cinco disciplinas estão ligadas à dimensão Relação Ser Humano-Sociedade; são elas: História da Educação Física, Perspectivas Filosóficas da Cultura Corporal, Filosofia da Educação, Sociologia da Educação e Introdução ao Estudo da Corporeidade.

b) Duas disciplinas e a Monografia estão ligadas à dimensão Produção do Conhecimento Científico e Tecnológico; são elas: Introdução à Metodologia Científica e Metodologia da Pesquisa;

c) Três disciplinas estão ligadas à dimensão Biológica do Corpo Humano; são elas: Anatomia Aplicada à Educação Física e Esportes, Fisiologia e Socorro em Urgências;

2. $\quad \mathrm{Na}$ Formação Específica;

a) Oito disciplinas e as Atividades Complementares estão ligadas à dimensão TécnicoInstrumental; são elas: Fisiologia do Exercício I, Cinesiologia, Psicologia da Educação, Psicomotricidade, Educação Física Adaptada, Educação Física na Educação Infantil, Educação Física no Ensino Fundamental, Educação Física no Ensino Médio;

b) Quatro disciplinas e o Estágio Curricular Supervisionado são ligados à dimensão DidáticoPedagógica: Didática, Didática de Educação Física I, Didática de Educação Física II e Educação Brasileira;

c) Doze disciplinas Obrigatórias e as Disciplinas de Livre Escolha estão ligadas à dimensão Culturais do Movimento Humano; são elas: Prática da Natação, Folclore Brasileiro: danças e folguedos, Fundamentos do Atletismo, Fundamentos da Natação, Fundamentos da Ginástica Artística, Fundamentos do Voleibol, Fundamentos do Basquetebol, Fundamentos do Handebol, Fundamentos do Futebol, Fundamentos da Capoeira, Educação Física e Ludicidade e Fundamentos da Ginástica.

As disciplinas são organizadas em Formação Específica e Formação Ampliada por causa da Resolução CNE/CES n ${ }^{\circ}$ 07/2004(Brasil, 2004) e, nesse contexto, articulam os conhecimentos da Educação Física, subdividindo-os nas Dimensões do Conhecimento. Tal Resolução CNE/CES nº 07/2004 (Brasil, 2004), entretanto, não conceitua e nem discute cada dimensão do conhecimento. Com isso, as Instituições de Ensino Superior têm liberdade para distribuir as disciplinas dentro da dimensão do conhecimento mais adequada, conforme a proposta apresentada. 


\subsection{Disciplinas, Carga Horária e Ementas: Bacharelado}

O curso de bacharelado em Educação Física possui uma carga horária total de 3.260 horas dividida em nove períodos. A carga horária total do curso divide-se em: 41 Disciplinas Obrigatórias, equivalentes a 2.280 horas; 360 horas de Disciplinas de Livre Escolha; 300 horas de Estágio Supervisionado; 120 horas de Monografia e 200 horas de Atividades Acadêmico-científico-culturais.

As 41 disciplinas obrigatórias do curso de bacharelado são divididas em Formação Ampliada e Formação Específica, que, por sua vez, são subdivididas em:

1. Na formação Ampliada;

a) Quatro disciplinas estão ligadas a dimensão Relação Ser Humano-Sociedade, são elas: História da Educação Física, Perspectivas Filosóficas da Cultura Corporal, Introdução aos Estudos do Lazer e Introdução ao Estudo da Corporeidade;

b) Duas disciplinas e a Monografia estão ligadas a dimensão Produção do Conhecimento Científico e Tecnológico, são elas: Introdução à Metodologia Científica e Metodologia da Pesquisa,

c) Duas disciplinas estão ligadas a dimensão Biológica do Corpo Humano, são elas: Anatomia Aplicada à Educação Física e Esportes e Fisiologia Geral;

2. Na Formação Específica

a) Treze disciplinas e as Atividades Acadêmico-científico-culturais estão ligadas a dimensão Técnico-Instrumental, são elas: Fisiologia do Exercício I, Fisiologia do Exercício II, Cinesiologia, EF para Portadores de Necessidades Especiais, Metodologia do Treinamento Esportivo, Atividades Físicas para Grupos de Risco, Desenvolvimento Motor e Aprendizagem Motora, Introdução à Bioestatística, Socorros em Urgência, Biomecânica I, Avaliação da Performance Humana, Bioquímica do Exercício e Administração, Gestão e Marketing Esportivo;

b) Uma disciplina e o Estágio Supervisionado estão ligados à dimensão Didático-Pedagógica, são elas: Planejamento e Metodologia do Ensino de Educação Física e Esportes;

c) Dezenove disciplinas Obrigatórias e as Disciplinas de Livre Escolha estão ligadas à dimensão "Culturais do Movimento Humano", são elas: Prática da Natação, Fundamentos do Atletismo, Fundamentos da Natação, Fundamentos da Ginástica, Fundamentos do Voleibol, Fundamentos do Basquetebol, Fundamentos do Handebol, Fundamentos do Futebol, Fundamentos da Capoeira, Educação Física e Ludicidade, Fundamentos da Musculação, Fundamentos do Judô, Fundamentos da Hidroginástica, Aplicação Pedagógica da Musculação, Aplicação Pedagógica do Futebol, Aplicação Pedagógica da Hidroginástica, Aplicação Pedagógica da Ginástica, Aplicação Pedagógica da Natação e Aplicação Pedagógica do Judô.

Assim como o PPP do curso de licenciatura, o PPP do bacharelado também não disponibiliza a ementa de todas as disciplinas obrigatórias do currículo, sendo necessário recorrer ao Plano de Curso da disciplina para ter acesso à bibliografia, conteúdos, avaliação etc. 


\section{4) ANÁLISE dos dados}

\subsection{Aproximações e distanciamentos entre os cursos: Disciplinas, Carga Horária e Ementas}

A carga horária dos cursos de licenciatura e bacharelado é diferente, com o bacharelado tendo no total 290 horas a mais do que a licenciatura e, referente ao estágio, a licenciatura ter mais 100 horas de cumprimento obrigatório do que o bacharelado, conforme pode ser visto na Tabela 1.

TABELA 1:

Relação dos componentes e comparação da carga horária entre os cursos.

\begin{tabular}{|l|l|l|}
\hline Atividade & Licenciatura & Bacharelado \\
\hline Disciplinas Obrigatórias & 1.890 horas & 2.280 horas \\
\hline Disciplinas de Livre Escolha & 360 horas & 360 horas \\
\hline Monografia & 120 horas & 120 horas \\
\hline Estágio & 400 horas & 300 horas \\
\hline Atividades Complementares & 200 horas & 200 horas \\
\hline Total & $\mathbf{2 . 9 7 0 ~ h o r a s ~}$ & $\mathbf{3 . 2 6 0 \text { horas }}$ \\
\hline
\end{tabular}

Fonte: Universidade 1, PPP da licenciatura e a do bacharelado (2006)

Já a Tabela 2 mostra que os cursos concentram seu maior número de disciplinas na dimensão do conhecimento "Culturais do Movimento Humano", seguido pela dimensão "Técnico Instrumental”. As disciplinas que são agrupadas a uma Dimensão do Conhecimento na licenciatura, não necessariamente obedecem à mesma classificação no bacharelado. Apesar do curso de bacharelado ser voltado para atuação extra-escolar, à atividade exercida pela profissional não está desvinculada da docência. No entanto, remetese a ideia que o graduado/bacharel em Educação Física deve possuir uma ampla gama de conhecimento advindo da área da biodinâmica. Entretanto, a licenciatura possui mais disciplinas na dimensão "Biológica do Corpo Humano”. A tabela 2 mostra a quantidade de disciplinas distribuídas por curso em cada Dimensão do Conhecimento. 
TABELA 2:

Número de disciplinas dentro das Dimensões do Conhecimento:

\begin{tabular}{|c|c|c|}
\hline Dimensão do Conhecimento & Licenciatura & Bacharelado \\
\hline Relação Ser Humano-Sociedade & 5 & 4 \\
\hline Produção do Conhecimento Científico e Tecnológico & 2 & 2 \\
\hline Biológica do Corpo Humano & 3 & 2 \\
\hline Técnico-Instrumental & \&. & 13 \\
\hline Didático-Pedagógica & 4 & 1 \\
\hline Culturais do Movimento Humano & 12 & 19 \\
\hline Total & 34 & 41 \\
\hline
\end{tabular}

Fonte: Universidade 1, PPP da licenciatura e a do bacharelado (2006).

\subsection{Disciplinas em Comum entre os cursos}

Ao compararmos as ementas, os planos de curso e a carga horária das disciplinas dos cursos de licenciatura e bacharelado em Educação Física, pode-se observar que os cursos possuem algumas disciplinas equivalentes ou idênticas, como mostra o Quadro 2:

QUADRO 2:

Relação das disciplinas iguais ou equivalentes entre os cursos

\begin{tabular}{|l|l|l|}
\hline \multicolumn{2}{|l|}{ Disciplinas iguais ou equivalentes entre os cursos de licenciatura e bacharelado } \\
\hline $\begin{array}{l}\text { História da Educação Física } \\
\text { Fundamentos da Capoeira }\end{array}$ & Fundamentos do Voleibol & $\begin{array}{l}\text { Anatomia Aplicada à Educação } \\
\text { Física }\end{array}$ \\
$\begin{array}{l}\text { Introdução ao Estudo da } \\
\text { Corporeidade } \\
\text { Fundamentos do Atletismo }\end{array}$ & Educação Física e Ludicidade & Educação Física Adaptada \\
Prática da Natação & Fundamentos do Futebol & Fundamentos do Basquetebol \\
Introdução à Metodologia Cientifica & Cinesiologia & Fundamentos da Natação \\
Socorros em Urgência & Fundamentos da Ginástica & Bioquímica EF \\
Fundamentos do Handebol & Metodologia da Pesquisa & $\begin{array}{l}\text { Perspectivas } \\
\text { Cultura Corporal }\end{array}$ \\
& Fisiologia do Exercício I & $\begin{array}{l}\text { Metodologia da Pesquisa em } \\
\text { Educação Física }\end{array}$ \\
\hline
\end{tabular}

Fonte: Universidade 1, PPP da licenciatura e a do bacharelado (2006).

A formulação do quadro de equivalência de disciplinas só é possível quando se acessa outros documentos além dos PPPs, uma vez que a Universidade 1 não fornece todas as informaçóes necessárias e apresenta a Matriz Curricular incompleta, com menos disciplinas do que o necessário para a formação. 
Diante da análise do Quadro 2, pode-se observar que os cursos possuem 24 disciplinas iguais ou equivalentes. Isso corresponde a $52,2 \%$ das disciplinas do curso de bacharelado que estão presentes no curso de licenciatura. Pode-se deduzir, assim, que mais da metade do curso de bacharelado é exatamente igual ao curso de licenciatura.

O percentual de igualdade entre os cursos, entretanto, pode tornar-se maior à medida que algumas das Disciplinas de Livre Escolha dos discentes de licenciatura são obrigatórias no curso de bacharelado. O curso de licenciatura oferece 27 Disciplinas de Livre Escolha, das quais quatro (04) são Disciplinas Obrigatórias do curso de bacharelado. Há, ainda, a possibilidade de o aluno escolher algumas disciplinas do curso de bacharelado ou de qualquer outro curso da Universidade, tendo como requisito de aceitação o número de vagas na turma, o Coeficiente de Rendimento (CR) do aluno e que a disciplina não tenha nenhum prérequisito (alguma disciplina cursada anteriormente).

Outra característica comum - referente à, possivelmente, uma escolha dos formuladores do currículo - mostra que os cursos têm uma base comum de disciplinas entre o $1^{\circ}$ e o $5^{\circ}$ período, sendo do $1^{\circ}$ ao $4^{\circ}$ praticamente idênticos, pois apresentam a maior quantidade de disciplinas iguais ou equivalentes, diferidos apenas pela ordem de algumas disciplinas entre os períodos.

Conforme previsto na metodologia, no próximo item serão analisadas as disciplinas iguais ou equivalentes, comuns aos cursos. Para tal, será utilizado os Planos de Curso das disciplinas que disponibilizam para o acesso via sítio eletrônico da Universidade 1. Desse modo, a seguir, serão analisadas e discutidas as 16 disciplinas (Quadro 3), buscando compreender se os Planos de Curso reproduzem um retrato organizado da concepção de currículo e dos objetivos dos cursos que estão expostos em seus PPPs.

\section{QUADRO 3}

Disciplinas iguais ou equivalentes entre os cursos e que possuem seus

Planos de Cursos disponíveis no sítio eletrônico da Universidade 1

\begin{tabular}{|c|c|c|}
\hline \multicolumn{2}{|l|}{ Disciplinas em comum com Plano de Curso disponível } \\
\hline Fundamentos do Atletismo & História da Educação Física & Fundamentos da Capoeira \\
\hline Fundamentos do Basquete & Bioquímica & Fundamentos do Voleibol \\
\hline Fundamentos do Futebol & Fisiologia & Introdução à Metodologia Científica \\
\hline Fundamentos da Ginástica & Fisiologia do Exercício I & $\begin{array}{l}\text { Metodologia da Pesquisa em } \\
\text { Educação Física }\end{array}$ \\
\hline Fundamentos da Natação & Anatomia Humana & \\
\hline Fundamentos do Handebol & Cinesiologia & \\
\hline
\end{tabular}

Fonte: Universidade 1, PPP da licenciatura e a do bacharelado (2006).

\subsection{Plano de Curso das Disciplinas em comum}

As disciplinas em comum entre os cursos estão predominantemente na dimensão do conhecimento Culturais do Movimento Humano. As disciplinas desta dimensão que são voltadas para os fundamentos, como "Fundamentos do Atletismo", "Fundamentos do Basquete", "Fundamentos do Futebol", entre outros, possuem algumas semelhanças em suas ementas. As ementas dessas disciplinas objetivam o ensino dos aspectos da origem e evolução de determinada modalidade, além dos fundamentos das técnicas e tática 
individuais e coletivas, as noções das regras e o contexto sócio-histórico-cultural, bem como os princípios didático-pedagógicos para o processo ensino-aprendizagem.

A disciplina "Fundamentos do Atletismo" apresenta a determinada ementa em ambos os cursos: "Aspectos da origem e evolução do Atletismo. Princípios das técnicas básicas das habilidades motoras específicas. Noções das regras e o contexto sócio-histórico-cultural. Princípios didático-pedagógicos para o processo ensino-aprendizagem" (PPP, 2006a 2006b, p.23). No Plano de Curso da própria disciplina que é comum aos dois cursos encontramos a ementa: "Vivência orientada e estudo reflexivo das metodologias para prática educativa de atletismo". Segundo as ementas, o estudo do atletismo deve acontecer de forma contextualizada, não se importando apenas com a técnica, com a execução de movimentos e com a aprendizagem de regras, mas utilizando o atletismo para pensar aspectos socioculturais e desenvolver competências metodológicas de forma reflexiva, pautadas no processo ensino-aprendizagem. Os objetivos da disciplina, no entanto, não estão de acordo com a proposta da ementa, pois apresentam objetivos apenas voltados para o ensino das técnicas, assim como as avaliações da disciplina e a bibliografia básica, demonstrando o aporte técnico dado à disciplina, se distanciando de uma perspectiva de ensino crítica.

O mesmo acontece na disciplina "Fundamentos do Basquete" com a ementa disponível no PPP (2006a; 2006b) que tem por objetivo abordar "aspectos da origem e evolução do Basquetebol. Fundamentos das técnicas e táticas, individuais e coletivas. Noções das regras e o contexto sócio-histórico-cultural. Princípios didático-pedagógicos para o processo ensino-aprendizagem" e no Plano de Curso há uma diferença para "vivência orientada e estudo reflexivo da metodologia para a prática educativa em Basquetebol". Ainda que a ementa traga uma preocupação em abordar o contexto sócio-histórico-cultural, a bibliografia referida não encontra apoio nos autores desses assuntos, uma vez que os autores a partir desses livros trabalham a perspectiva tecnicista do basquetebol.

$\mathrm{Na}$ disciplina "Fundamentos da Ginástica", tanto a ementa quanto os objetivos utilizam da técnica e da aptidão física como fins principais. Um objetivo para o discente é aprimorar os níveis de aptidão física através dos exercícios ginásticos. Dentre os objetivos gerais encontrados no Plano de Curso, encontramos um tópico que trata como responsabilidade da disciplina conscientizar e favorecer o senso crítico do aluno. A bibliografia, porém, parece não estar ligada a esse objetivo, pois não dispõe de referências de autores ou de conteúdos que tenham esta perspectiva.

Essa relação discrepante entre as ementas nos PPPs, os objetivos das disciplinas e a bibliografia básica se repete por outras disciplinas de fundamentos, como: "Fundamentos da Natação", "Fundamentos do Handebol”, "Fundamentos do Voleibol" e "Fundamentos do Futebol”. Os objetivos das disciplinas também não são atendidos quando comparados à sua bibliografia, já que os autores trabalham numa perspectiva teórica que tende privilegiar o ensino da técnica. Na prática, isso pode culminar em um ensino tecnicista, ou seja, o ensino dos componentes técnicos em detrimento dos aspectos reflexivos da prática educativa, não demonstrando, portanto, a visão crítica ressaltada em diversos pontos do PPP.

Já nas disciplinas "Fundamentos da Capoeira" e "História da Educação Física" os Planos de Curso e o PPP se mostram numa proposta diferente quando comparadas às outras disciplinas. Isso porque na disciplina "Fundamentos da Capoeira" a ementa, os objetivos, a bibliografia básica e a bibliografia complementar se aproximam da proposta curricular do PPP à medida que trabalham com bibliografias e objetivos que estão para além da prática descontextualizada. Essa relação pode afastar as aulas de uma perspectiva em que a técnica do movimento é fim de si mesma.

A disciplina "História da Educação Física" pertence à dimensão "Relação Ser Humano-Sociedade". O objetivo apresentado pela disciplina é desenvolver nos alunos a consciência crítica necessária para reconhecer as diferentes abordagens da Educação Física. Outro objetivo é de traçar estilos próprios de ensino quando necessário a partir da abordagem histórico-crítica frente ao mercado e ao ensino da Educação Física. Nesse caso, a bibliografia básica e complementar da disciplina expressa um viés crítico pela fenomenologia e pelo marxismo. 
As disciplinas que possuem o viés das Ciências Naturais como "Bioquímica", "Fisiologia EI", "Fisiologia do Exercício I", "Anatomia Humana" e "Cinesiologia” estão voltadas para pensar o corpo humano através das Ciências Naturais, não demonstrando em suas ementas e Planos de Curso atrelar o seu conhecimento a uma perspectiva crítica, junto as Ciências Humanas e Sociais.

As disciplinas "Introdução à Metodologia Científica" e "Metodologia da Pesquisa em Educação Física" são voltadas para a pesquisa, fornecendo aos alunos ferramentas teórico-metodológicas para produção científica. Em ambos os cursos as disciplinas se encontram na Dimensão do Conhecimento "Produção do Conhecimento Científico e Tecnológico". Segundo os PPPs (2006a; 2006b), a "Introdução à Metodologia Científica" deve fornecer ao aluno

uma compreensão dos princípios básicos da Metodologia Científica na dimensão de sua relação com o pensamento filosófico e a epistemologia, buscando um entrosamento dos fundamentos teóricos da produção científica com o processo de construção do conhecimento em Educação Física (p.25).

Já na disciplina "Metodologia da Pesquisa" espera-se que ao final o aluno esteja capacitado para realizar o projeto de monografia e em seguida a própria monografia. Nessa proposta, da Dimensão do Conhecimento "Produção do Conhecimento Científico e Tecnológico" apesar de só ter duas disciplinas, parece que o documento ressalta a importância da pesquisa para a capacitação do profissional. Cabe compreender que a dimensão do pensamento filosófico e as epistemologias do conhecimento permitem ao aluno identificar diferentes formas de construção do conhecimento, conhecer e analisar as hipóteses e os resultados de diversas ciências, bem como entender aspectos políticos, filosóficos e históricos.

Assim sendo, dada às características do processo de aproximação e distanciamentos entre os cursos de licenciatura e bacharelado da Universidade 1 descritos nesse item 4, cabe agora, no item 5 à frente, tecer algumas considerações para amalgamar a análise.

\section{5) Consideraçoes sobre a ANÁlise realizada}

A partir dos dados levantados, pode-se inferir que os cursos de Educação Física da Universidade 1 (licenciatura e bacharelado):

1. Possuem componentes curriculares comuns, ao ponto de confundirem-se entre si, dificultando um processo identitário;

2. Não apresentam elementos que sustentem epistemologicamente duas formações distintas tal como estão caracterizados nos currículos pesquisados, considerando também os dados históricos da formação superior em Educação Física;

3. Atende a legislação vigente, mas, talvez por isso, acaba por recair na mesma lógica “ $3+1$ ”, histórica de cursos com formação em licenciatura e bacharelado, só que agora com maior carga horária e tempo de formação;

4. Atende a conveniência dos alunos, pois estes podem finalizar ambos os cursos e menos tempo, atendendo à legislação e permitindo que atuem em diferentes espaços de forma legalizada;

5. Conseguem uma economia de recursos, com otimização de professores e turmas flexíveis por entre os cursos, além dos materiais, insumos, salas de aula, laboratórios, instalações etc., sugerindo que pode estar ocorrendo o mesmo em outras universidades públicas e particulares;

6. Mostram-se com uma intensa sinergia, possível porque historicamente e, do ponto de vista da atuação, tais cursos permitem essas aproximações por conta de uma lógica de demanda mercadológica e social por novos campos de atuação.

7. Tem perfil similar porque, dentre outros fatores, em especial a atuação dos egressos deverá ocorrer no ofício de professores (ainda que haja uma demanda semântica pelo termo "profissionais", principalmente por causa do processo de regulamentação da profissão), ou seja, pode haver 
igualdade na atividade fim entre egressos de ambos os cursos, só que em espaços de atuação diferentes.

Posto isto, ressalte-se, ainda, à guisa de conclusão da análise realizada, que a lógica constituída na confecção do currículo da Universidade 1, parece atender adequadamente a legislação vigente. Talvez por isso, contudo, acaba por recair na mesma lógica " $3+1$ ", histórica de cursos com formação em licenciatura e bacharelado, só que agora com maior carga horária e tempo de formação.

Cabe agora, após o percurso analítico-descritivo delineado, fruto de aspectos empíricos e documentais do caso da Universidade 1 analisado, perscrutar alguns elementos, como a concepção curricular, para delimitar o escopo teórico necessário com vistas à continuidade à análise, trazendo o princípio educativo de Gramsci ${ }^{1} 4$, conforme previsto nos termos teórico-metodológicos do presente artigo.

\section{6) Elementos teóricos de ANÁlise}

Ao analisar a redação da prescrição de Concepção de Currículo - que é a mesma para as duas formações -observa-se que há uma preocupação explícita com a formação do estudante, de forma pretensa a prepará-lo para o mercado de trabalho e atender assim a demanda da mão de obra que a sociedade moderna exigiria. Há, nesse percurso, uma exigência de profissionais cada vez mais produtivos, em detrimento do desenvolvimento da capacidade reflexiva dos futuros trabalhadores. $O$ trecho referente à concepção de currículo acima descrito choca-se com o tópico V (Perfil do Egresso) do PPP da Universidade 1. Este propõe que o estudante "possua uma ampla visão da realidade social, política, cultural e econômica do País, consciente das reais necessidades e possibilidades do cidadão" (PPP, 2006a; 2006b, p.16).

Nesse sentido, Gramsci (2001) retrata que a formação do trabalhador à serviço estrito do mercado consiste em uma formação fragmentada e alienada para o desenvolvimento do trabalho manual, sem a capacidade de serem dirigentes de seu próprio trabalho e de sua vida social. Essa concepção do autor nos remete ao processo de alienação do trabalhador que na ausência do pensamento crítico histórico-dialético, pode tornar-se mão de obra barata.

Cabe ressaltar, em outro aspecto, que a EF no Brasil sofreu influência de diversas correntes em determinados tempos históricos, o que direcionava sua concepção pedagógica na compreensão de homem e de mundo. Isso não garantiu que as compreensões sobre a Educação Física acompanhassem mecanicamente - embora tenham ocorrido - tais influências. Como exemplo dessa ocorrência, podemos citar correntes pedagógicas tradicionalistas ou da aptidão física que ainda permanecem presentes em currículos mesmo após o advento de ascensão da perspectiva sociocultural, a partir dos anos 1980.

Desse modo, o currículo se caracteriza como um campo em disputa por diferentes concepções pedagógicas, mas, podendo conter termos usuais comuns a essas diferentes concepções, que não necessariamente possuam o mesmo sentido, como é o caso, na UNIVERSIDADE 1, de: "formação de um novo profissional", "reflexivo", "crítico", "concepção reflexiva", "visão da realidade social, política, cultural e econômica”, entre outros. Esses termos parecem tender, nos PPPs analisados, para qualquer direção. Chama atenção essa possibilidade de formação acrítica quando cotejado ao pensamento de Gramsci (2001) porque "o enorme desenvolvimento obtido pela atividade e pela organização escolar (em sentido lato) nas sociedades [...] indica a importância assumida no mundo moderno pelas categorias e funções intelectuais” (p. 19).

Por outro lado, os itens presentes no Perfil do Egresso mostram a preocupação com a atuação do profissional no exercício docente. Ainda que o graduado/bacharel atue na área não escolar, ele não deixa de exercer, na maioria das atividades, a função de professor, educador, tendo como responsabilidade desenvolver subsídios teórico-metodológicos coerentes que justifiquem sua prática profissional. Diferente de outras áreas que se dividem em licenciatura e bacharelado, nas quais o bacharel trabalha especificamente com a pesquisa, o bacharel ou graduado em Educação Física não tem, de forma usual, sua atuação desvinculada da docência. 
Pode-se perceber que os objetivos gerais dos cursos, o perfil dos egressos, a concepção currículo, bem como mais da metade da matriz curricular dos cursos se equivalem, dessa maneira, podemos afirmar que os cursos possuem muitos pontos que são comuns à formação do licenciado e do graduado/bacharel. Observa-se que em diversos tópicos do PPP de ambos os cursos há uma proposta de formação voltada para a formação de indivíduos críticos, capazes de pensar e entender os fenômenos que orbitam a sociedade, sendo capazes de intervir através da sua prática profissional.

Na perspectiva de Gramsci (2001), para atingir as condições objetivas de desenvolvimento da consciência crítica e de emancipação é necessário que as relações de trabalho não sejam dicotomizadas (trabalho intelectual $x$ trabalho manual), como é desenvolvida na sociedade industrial fordista-taylorista, nem atendam aos ditames mercadológicos. Daí sobressai-se a importância de disciplinas e um currículo que: alie teoria e prática pedagógica (práxis); amplie progressivamente a autonomia dos sujeitos e valorize processos organizativos autogestionários, dentre outros modos de implementar o projeto de formação dos futuros profissionais.

Outro ponto recorrente nos documentos consultados é a questão da pesquisa como parte fundamental da formação do aluno pela universidade e como possibilidade de atualização durante o exercício da profissão. O PPP atribui à pesquisa a possibilidade do professor continuar estudando e se atualizando sobre diversas áreas do conhecimento, como é o caso da formação continuada. Em uma análise gramsciana, Malina (2016) afirma que diante do mundo moderno, o fazer "intelectual desempenha um papel importante na sociedade, que busca a ampliação das capacidades do indivíduo, desenvolvendo e multiplicando espaços para sua especialização e aperfeiçoamento, tanto na ciência quanto nas atividades técnicas” (p. 163). Dito de forma específica, "na chamada civilização moderna as atividades práticas se tornaram bem complexas, junto a uma mistura de ciências" (Dias, Malina e Azevedo, 2017, p. 56).

A análise desses pontos comuns indica uma perspectiva de formação única, não justificando o porquê de se dividir em licenciatura e bacharelado a formação em Educação Física na Universidade 1.

Não é raro encontrar no PPP a repetição de termos como "criar nos novos profissionais", "consciência", "reflexivo", "crítico", "formação contínua”, "autônomo", "transformadora”, "crítico-reflexiva”, "intervenção profissional”, entre outros. Na teoria crítica de currículo, esses termos nos remetem a pensar em uma formação para a totalidade do ser e que também forneça ao aluno subsídios básicos para a atuação profissional, distanciando-se da formação fragmentada e alienada. Uma proposta de formação humana com base no princípio educativo de corte gramsciano, corrobora com a perspectiva crítica de currículo e formação, pois sugere a superação da dicotomia entre trabalho intelectual e trabalho manual, que quando realizada de forma fragmentada coopera para a acentuação do processo de alienação do trabalhador. Assim, quando se pensa em formação crítica, ainda mais em relação à pesquisa, "exige-se uma luta rigorosa contra os hábitos do diletantismo, da improvisação, das soluções “oratórias” e declamatórias (Gramsci, 2001, p. 35).

A proposta e os objetivos da formação destinada aos alunos encontrados no PPP devem estar condizentes com os currículos prescritos, pois é através dele que essa concepção de formação irá ganhar materialidade de fundamentos epistemológicos, teórico-metodológicos e didáticos. Ao compararmos a proposta de formação dos PPPs com a base comum de disciplinas dos cursos, encontramos alguns pontos que afastam seus objetivos das próprias disciplinas dos cursos. À medida que os PPPs propõem uma formação crítica, algumas disciplinas caminham para o lado contrário, com objetivos, conteúdos, bibliografia e referenciais teóricos que não elucidam uma visão crítica de homem e mundo para os alunos.

Nessa perspectiva, os dados levantados submetidos à análise, apontam para um ecletismo epistemológico no conjunto dos documentos curriculares, mesmo com a utilização de determinados termos (crítico, reflexivo, autônomo, consciente etc), distanciando os alunos de uma visão emancipatória. A exigência de fundo é da formação de profissionais produtivos em detrimento do desenvolvimento da capacidade reflexiva dos futuros trabalhadores. 
Considera-se, a partir de Gramsci (2001), que se deve integrar a escola básica e superior, com vistas a que esta formação possa emancipar e elevar o pensamento crítico do homem para a formação do intelectual. Nas palavras desse autor:

"o problema da criação de uma nova camada intelectual, portanto, consiste em elaborar criticamente a atividade intelectual que cada um possui em determinado grau de desenvolvimento, modificando sua relação com o esforço muscular-nervoso no sentido de um novo equilíbrio e fazendo com que o próprio esforço muscular-nervoso, enquanto elemento de uma atividade prática geral, que inova perpetuamente o mundo físico e social, torne-se o fundamento de uma nova e íntegra concepção de mundo" (p. 53).

Com Gramsci (2001), é possível opor à escola unitária e ao princípio educativo, modelos curriculares prescritos de cursos, tais como:

O da escola tradicional, oligárquica, não exatamente pelo seu método e ensino, mas por ser acessível apenas à elite, formando futuros dirigentes;

O da escola profissional que cria uma falsa impressão de ser democrática, objetivando criar novas estratificações sociais, passando o profissional de não-qualificado para qualificado, atendendo às novas demandas do mercado.

Dessa forma, tendo o trabalho como princípio educativo pode-se aferir que os cursos de Educação Física da Universidade 1 aproximam-se da concepção de, conforme o pensamento gramsciano acima colocado, escola profissional, cuja estrutura básica está na preparação de mão de obra para o mercado, a fim de resolver problemas práticos e imediatos. Esse tipo de escola reitera a dicotomia entre trabalho intelectual e trabalho manual, dirigentes e não-dirigentes, classe dominante e classe subordinada. Nesse sentido, fornece ao aluno subsídios para se especializar em um tipo de trabalho, de forma a beneficiar o capitalista que extrairá cada vez mais da força de trabalho desse indivíduo.

O aluno submetido a esse tipo de educação deve tornar-se produtivo, assalariado e consumidor, perpetuando o ciclo de expansão do capital. O que Gramsci (2001) ressalta de mais preocupante nessa escola é que ela é orgânica ao capitalismo dando, entretanto, uma pseudovisão de democracia na qual os alunos estariam supostamente inseridos.

\section{7) Conclusoes gerais}

Os currículos dos cursos de Educação Física existentes em universidades públicas brasileiras expressam características que levaram a necessidade de um estudo de caso particular. Dada à conformação do tipo estudo de caso, podem-se propor generalizações a partir dessa metodologia orientadora. No estudo em tela, entretanto, observou-se alguns elementos descritos que permite supor um formato recorrente de convergência entre cursos de licenciatura e bacharelado, o que justificaria os resultados gerais de igualdade e/ou superposição de disciplinas, ementas e, de certa forma, o próprio escopo desses cursos. No entanto, a Resolução CNE/CES nº 06/2018 desconsidera a relação de igualdade entre as disciplinas curriculares da licenciatura e do bacharelado, ratificando a formação fragmentada em Educação Física, tanto no princípio da formação humana quanto nas possibilidades de atuação no mundo do trabalho.

Diante desse quadro, é nesse contexto de disputa de espaços e embates característicos dos currículos que se insere o PPP do curso Educação Física da Universidade 1. Esta instituição explana em seus PPPs a perspectiva de currículo, seus objetivos, o perfil do egresso, entre outros pontos fundamentais para entendermos sua proposta de formação. Analisando e interpretando o currículo dos cursos de Educação Física constatam-se pontos de discrepância que impossibilitam uma visão crítica na formação:

1. Os diferentes objetivos entre formação crítica e mercado, que entre si não se contemplam, se pensarmos que na sociedade atual a formação de um profissional crítico-reflexivo entra em 
divergência com as necessidades do mercado, que prioriza de um profissional com capacidade crítica geral mínima, mas com um trabalho técnico potencializado;

2. A falta de aproximação entre disciplinas que possuem uma base comum nos dois cursos com as propostas de formação humana do PPP, à medida que mostram, predominantemente, um caráter técnico, baseado nas Ciências Naturais para explicar o homem e o mundo, diferente da proposta dos PPPs, e;

3. O ecletismo presente nos PPPs e nos currículos, com autores que demonstram diferentes visões sobre a sociedade.

De maneira característica, no currículo pesquisado a separação entre cursos distintos da formação superior em Educação Física não parece ocorrer de fato, dada à quantidade de disciplinas e ementas em comum. Isso não auxilia uma proposta de formação crítica e reflexiva e autônoma uma vez que essa divisão pode não permitir ao aluno observar diferentes locais de atuação possíveis no ofício docente em Educação Física.

As novas Diretrizes Curriculares em Educação Física reforçadas no texto da Resolução CNE/CES n 06/2018 vêm confirmar um projeto de formação unilateral e fragmentada, pois, além de regulamentarem a divisão do curso em duas modalidades distintas, não aponta um escopo teórico crítico de formação. Numa perspectiva oposta a defendida nesse trabalho, os cursos superiores em Educação Física corroboram com a mercadorização do ensino e a lógica empresarial capitalista, pois deixa com que as IES escolham de forma arbitrária quais modalidades serão oferecidas e como serão oferecidas, como pode ser visto no Art. 30.

Na perspectiva gramsciana, para a formação de um novo homem, capaz de ser um dirigente de sua própria vida social, é necessário ter autonomia, ativismo e espontaneidade que se articulam dialeticamente no interior da escola. Como uma consciência crítica não está alicerçada predominantemente em uma base educacional crítica sistematizada nos currículos da Universidade 1 -, torna-se difícil um PPP com objetivos de formação factíveis para o sujeito que vivencia o currículo. Dessa forma, pode tornar-se predominante a vigência do currículo oculto, criando um desequilíbrio e uma responsabilidade exagerada na relação entre professores e alunos no processo ensino-aprendizagem, para além do PPP.

Para obtenção de generalizações precisas, entretanto, cabe ponderar a necessidade de mais dados de outros cursos, tais como os que aqui foram levantados e analisados, para conclusões mais assertivas. Devido a características ambíguas do currículo da Universidade 1, no entanto, há espaços em disciplinas para que, vivenciando o currículo, a formação profissional possibilite a compreensão dos fenômenos sociais que permeiam a sociedade em que se vive. Nesse sentido, defende-se aqui uma proposta de formação ampliada na perspectiva omnilateral, resultante da unificação curricular da licenciatura e do bacharelado resultante da uma Licenciatura Ampliada.

\section{REFERÊNCIAS}

Antunes, AC. (2007). Mercado de Trabalho e Educação Física: aspectos da preparação profissional. RevEduc, 10(10), 141-149.

Azevedo, ÂCB. (2016). Fundamentos da Teoria Curricular para (Re)Formulação de Projetos Pedagógicos em Educação Física. Campo Grande:. Editora UFMS.

Azevedo, ÂCB. (2013). História da Educação Física no Brasil: Currículo e Formação Superior. Campo Grande: Editora UFMS.

Baffi, MAT. (2002). Modalidades de pesquisa: um estudo introdutório. Petrópolis.

Betti, M., Knijnik, J., Venâncio, L., Sanches Neto, L., y Daólio, J. (2014). Fundamentos filosóficos e antropológicos da Teoria do Se-movimentar e a formação de sujeitos emancipados, autônomos e críticos: o exemplo do currículo de Educação Física do Estado de São Paulo. Movimento, 20(4), 1631-1653. Porto Alegre. 
Brasil. CNE. (2002). Resolução no 1, de 18 de Fevereiro de 2002. Institui as Diretrizes Curriculares Nacionais para a formação de professores da educação básica, em nível superior, curso de licenciatura, de graduação plena. Conselho Pleno do Conselho Nacional de Educação, Brasília.

Brasil. CNE. (2004). Resolução no 7, de 31 de Março de 2004. Institui as Diretrizes Curriculares Nacionais para os cursos de graduação em Educação Física, em nível superior de graduação plena. Câmara de Ensino Superior do Conselho Nacional de Educação, Brasília.

Brasil. CNE. (2018). Resolução no 584, de 03 de Outubro de 2018. Institui as novas Diretrizes Curriculares Nacionais do curso de graduação em Educação Física. Câmara de Ensino Superior do Conselho Nacional de Educação, Brasília.

Dias, LRV., Malina, A., y Azevedo, ÂCB. (2017). Formação Profissional e Formação Humana. In A. C. B. Azevedo \& A. Malina (Eds). Formação Profissional e Formação Humana em Educação Física. (pp. 45-68). Campo Grande: Editora UFMS.

Gil, AC. (2008). Métodos e Técnicas de Pesquisa Social. 6a. São Paulo: Atlas S. A.

Goodson, IF. (2008). Currículo: Teoria e História. Petrópolis: Vozes.

Gramsci, A. (2001). Cadernos do cárcere. Os intelectuais. Oprincípio educativo. Jornalismo. Tradução de Carlos Nelson Coutinho. Volume 2, Rio de Janeiro: Civilização Brasileira.

Lupton, D. (2003). Desenvolvendo-me por inteiro": cidadania, neoliberalismo e saúde contemporânea no currículo de Educação Física. Movimento, 9(3), 11-31.

Malina, A. (2016). Gramsci e a Questão dos Intelectuais. Campo Grande: Editora UFMS.

Meirinho, M., y Osório. A. (2010). O Estudo de Caso como Estratégia de Investigação em Educação. EDUSER: revista de educação, 2(2), 49-65.

Neira, MG. (2017). Desvelando Frankensteins: interpretações dos currículos de Licenciatura em Educação Física. Rev. Int. de Form. de Professores (RIFP), 2(2), 189-211.

Rivilla, AM., Garrido, MCD., y Gonçalves, FR (2011). Formación Del Profesorado Universitario en lãs Competencias Docentes. Rev. hist.edu.latinoam 17(13), 119-138.

Silva, TT. (2002). Documentos de identidade: uma introdução às teorias do curriculo. Belo Horizonte: Autêntica.

Triviños, ANS. (1987). Introdução à Pesquisa em Ciências Sociais: a pesquisa qualitativa em Educação. São Paulo: Atlas.

Universidade 1. (2006a). Projeto Político-Pedagógico do curso de licenciatura.

Universidade 1. (2006b). Projeto Político-Pedagógico do curso de bacharelado.

Ventura, MM. (2007). O Estudo de Caso como Modalidade de Pesquisa. Rev SOCERJ, 20(5), 383-386.

Vieira, RAG., y Neira, MG., Identidade docente no ensino superior de educação física: aspectos epistemológicos e substantivos da mercantilização educacional. Movimento, 22(3), 783-794.

\section{Notas}

1 Além dos PPPs, também poderão ser analisados documentos complementares para maior detalhe dos dados, como as Ementas e o Plano de Curso das disciplinas que compóem as modalidades do curso.

2 http://www.portal.mec.gov.br; http://www.emec.mec.gov.br;

3 Entende-se, na presente pesquisa, por disciplinas iguais aquelas que quando comparadas apresentam os três critérios seguintes: 1) mesmo nome; 2) mesma carga-horária e; 3) mesma ementa. Como disciplinas equivalentes consideram-se aquelas que possuem um ou dois critérios iguais, podendo o terceiro critério variar.

4 Optou-se por fazer a relação entre os cursos comparando o currículo e as disciplinas da graduação/bacharelado com a licenciatura por se entender que os cursos de Nível Superior em Educação Física, inicialmente, eram oferecidos na modalidade de Licenciatura Plena, que abarcava as duas formações. Desse modo, parte-se do pressuposto que o curso de bacharelado, por ser mais recente, possa ter mais relações com o curso de licenciatura.

5 Visando preservar a instituição pesquisada, o PPP será citado e referenciado como UNIVERSIDADE 1. Projeto PolíticoPedagógico do curso de licenciatura, 2006a e UNIVERSIDADE 1. Projeto Político-Pedagógico do curso de graduação, $2006 b$ para os cursos de licenciatura e graduação/bacharelado, respectivamente. 